\title{
Microbial sulfate reduction and organic sulfur formation in sinking marine particles
}

\author{
M. R. Raven ${ }^{1 *}$, R. G. Keil ${ }^{2}$, S. M. Webb ${ }^{3}$ \\ 1Department of Earth Science, University of California Santa Barbara, Santa Barbara, CA 93117, USA. 2School of Oceanography, University of Washington, Seattle, WA \\ 98195, USA. ${ }^{3}$ Stanford Synchrotron Radiation Lightsource, Stanford University, Menlo Park, CA 94025, USA. \\ *Corresponding author. Email: raven@ucsb.edu
}

Climate change is driving an expansion of marine Oxygen Deficient Zones, which may alter the global cycles of carbon, sulfur, nitrogen, and trace metals. Currently, however, we lack a full mechanistic understanding of how oxygen deficiency affects organic carbon cycling and burial. Here, we show that 'cryptic' microbial sulfate reduction occurs within sinking particles from the Eastern Tropical North Pacific Oxygen Deficient Zone, and that some microbially-produced sulfide reacts rapidly to form organic $S$ that is resistant to acid hydrolysis. Particle-hosted sulfurization could enhance carbon preservation in sediments underlying $\mathrm{O}_{2^{-}}$ deficient water columns and serve as a stabilizing feedback between expanding anoxic zones and atmospheric $\mathrm{CO}_{2}$. A similar mechanism may help explain more extreme instances of organic carbon preservation associated with marine anoxia in Earth history.

The oxygen deficient zones (ODZs) of the Eastern Tropical Pacific and Arabian Sea, which currently represent $\sim 0.35 \%$ of the total volume of the ocean (1), are expanding rapidly in apparent response to anthropogenic climate change (2-5). Concentrations of dissolved $\mathrm{O}_{2}$ in ODZs are below $\sim 1 \mu \mathrm{M}$ and may be effectively zero $(<10 \mathrm{nM}(6))$. Without available $\mathrm{O}_{2}$, animals are largely excluded and microorganisms must rely on alternative electron acceptors like nitrate, ferric iron, and sulfate to respire organic matter (OM). Microbial sulfate reduction (MSR), which produces sulfide, is canonically expected to occur only when more energetically favorable electron acceptors like nitrate have been locally depleted (7). Intriguingly, however, there is emerging molecular and geochemical evidence that suggests MSR may occur in ODZs despite plentiful dissolved nitrate $(8,9)$. Active MSR in ODZs could fundamentally alter the biogeochemical cycles of other elements because any sulfide produced could react rapidly with both metals (10) and organics (11) - a process called 'sulfurization.' During more severe periods of ocean deoxygenation in Earth history like the Cretaceous Ocean Anoxic Events, reactions with sulfide were globally significant sinks for both dissolved trace metals (12) and potentially atmospheric $\mathrm{CO}_{2}$ (13). Still, we do not yet know whether MSR is significant in ODZs and how it impacts fluxes of organic carbon to the sediments.

Due to its potential to affect global geochemistry, substantial effort has been devoted in recent years to find evidence of active microbial sulfur cycling within ODZs. Sulfur-cycling transcripts and gene sequences have been detected in both ODZs of the eastern Pacific $(8,9,14)$, the Washington margin
(15), and the Arabian Sea (16), while cadmium loss, attributed to CdS formation, was reported in the Northeast Pacific (17). Sulfide was detected in large marine snow from the San Juan Islands (18), and low rates of sulfide production in the ODZ offshore Chile were measured in the water column via radiolabeling experiments (9). Despite this progress, none of this work has yet yielded rates of MSR within the large, sinking particles that are the most probable locations for this metabolism (19), or has explored the impact of sulfide on the composition of sinking organic matter. To predict how expanding ODZs will impact the cycles of carbon and metals in the ocean, we need to know whether MSR and organic matter sulfurization are significant processes in sinking ODZ particles.

We tested the hypothesis that MSR occurs in large particles sinking through the Eastern Tropical North Pacific (ETNP) ODZ by concentrating sinking particles, incubating them with radiolabeled sulfate, and characterizing the products of reactions with any resulting sulfide (20). We deployed a surface-float-tethered particle trap with a 2-m-diameter, 50$\mu \mathrm{m}$-mesh net (21) from the R/V Roger Revelle four times in April and May 2018: once at a relatively low particle flux site ('P2,' $200 \mathrm{~km}$ from the Mexican coast, $17.0^{\circ} \mathrm{N} \times 107.0^{\circ} \mathrm{W}$, $\sim 3500 \mathrm{~m}$ water depth), which included a large-particle-free control, and three times at a relatively high particle flux site ('P1,' $\sim 50 \mathrm{~km}$ from shore, $20.3^{\circ} \mathrm{N} \mathrm{x} 106.1^{\circ} \mathrm{W}, \sim 1500 \mathrm{~m}$ water depth). Particles were trapped at the depth of the secondary nitrite maximum (120-143 $\mathrm{m}$ at P1 and $147 \mathrm{~m}$ at P2; fig. S1), which represents the depth of most intense nitrate reduction and thus the highest expected rates of anaerobic organic 
matter cycling (19). Particles for MSR (sulfide production) rate measurements were transferred from the anoxic particle collector and the net wash to serum bottles and incubated for $\sim 24$ hours in the dark with radiolabeled sulfate. After stopping microbial activity in the incubations with excess zinc acetate, we isolated acid-volatile sulfides (AVS, including both dissolved $\mathrm{H}_{2} \mathrm{~S}$ and metal monosulfides) and measured radioactivity in sulfate, AVS, and hydrolysis-resistant solids. This sampling approach allows us to focus specifically on processes within large, fast-sinking particles, which have been shown to develop internal redox gradients $(18,22,23)$ and therefore have the highest probability of supporting MSR. If rates of nitrate utilization within large particles exceed the diffusive resupply of nitrate from the water column, microenvironments within the particle can theoretically support MSR.

The vast majority of radiolabeled sulfide produced by MSR in our incubations is expected to either reoxidize or react with metals or organics to form solids (24). Because we did not add sulfide to our incubations as a trap (9), the AVS we measured (Fig. 1 and table S1) is likely composed mostly of iron monosulfides rather than dissolved sulfide. Based on our processing methods, radiolabeled $\mathrm{S}$ accumulated in the hydrolysis-resistant residual solid phase could potentially include elemental S, organic S, and/or pyrite. Below, we show that this phase is organic $\mathrm{S}$, and so we use that term throughout. P1 experiments (Fig. 1 ) accumulated as much as $171 \pm 10.8$ $(2 \sigma) \mathrm{nmol}$ AVS or $1711 \pm 100 \mathrm{nmol}$ organic S in 24 hours. P2 experiments contained fewer macroscopic aggregates and did not accumulate any resolvable AVS. The ratio of organic $S$ to AVS produced was variable, which could reflect differences in the reactive iron content of different particle populations. These results also highlight that organic $\mathrm{S}$, which is traditionally not measured as part of radiosulfur incubations, can be a major sink for MSR-derived sulfide.

In order to scale the $\mathrm{S}$ cycling rates in our bottles to the water column, we need to assess particle settling rates. Cavan et al. found near-shore particle sinking rates in the ETNP that ranged from $\sim 2$ to $\sim 120 \mathrm{~m} /$ day (25), although the vast majority of particle mass was present in the slow-sinking pool with fluxes closer to $6.5 \mathrm{~m} /$ day. An average sinking rate of 6.5 $\mathrm{m} /$ day, for a two-meter-diameter net and one-liter collector, would imply a concentration factor of $20,420 x$; an average sinking rate of $30 \mathrm{~m}$ /day would imply a concentration factor of 94,245x. Volume-corrected minimum MSR rates at P1 (average, $n=8$ ) are thus approximately $14 \mathrm{pM} / \mathrm{hr}$ (for $6.5 \mathrm{~m} /$ day,) or $3.0 \mathrm{pM} / \mathrm{hr}$ (for $30 \mathrm{~m} /$ day). For comparison, measured MSR rates were about 26 times higher $(\leq 360 \mathrm{pM} / \mathrm{hr})$ for water samples from the highly productive, $\mathrm{O}_{2}$-deficient Chilean margin, where surface chlorophyll-a concentrations were correspondingly $\sim 22$ times higher $(\sim 16 \mu \mathrm{g}$ chl-a/L off Chile (9) vs. $\sim 0.7 \mu \mathrm{g} \mathrm{chl}-\mathrm{a} / \mathrm{L}$ at P1). Particle-hosted MSR rates in the
ETNP are therefore roughly comparable to previously reported water-column MSR rates (9) after scaling for local productivity.

By assuming that two organic carbon atoms are oxidized for each sulfate molecule reduced (7), we can also estimate the contribution of MSR to carbon oxidation rates in sinking ETNP particles. An average of at least $0.68 \mu \mathrm{mol}$ of sulfide per day was produced in bottles from the high-flux site P1 (average, $n=8$ ), which is equivalent to $\sim 1.4 \mu \mathrm{mol} /$ day organic $\mathrm{C}$ respiration. The exact mass of carbon in these bottles is not known, so we report calculations for both our best estimate ( $5 \mathrm{mg} \mathrm{C} /$ bottle, see fig. S2) and the flux measured at another near-shore ETNP site (equivalent to $\sim 20 \mathrm{mg} \mathrm{C} /$ bottle (25)). We assume an organic carbon turnover rate for fast-sinking particles of $12 \%$ per day $(25,26)$. For $5 \mathrm{mg}(20 \mathrm{mg})$ organic carbon in each bottle, this turnover rate would suggest a total organic carbon respiration of $50 \mu \mathrm{mol} \mathrm{C} /$ day $(200 \mu \mathrm{mol}$ $\mathrm{C} /$ day), which would mean that MSR accounts for $2.8 \%(0.7 \%)$ of the total expected respiration. Bianchi et al. (19) predicted that $\sim 1 \%$ of depth-integrated respiration in the ETNP ODZ may be driven by MSR; our estimates for the contribution of MSR to total carbon respiration at our high-particle-flux site $(0.7-2.8 \%)$ are consistent with these theoretical predictions.

We identified the speciation of sulfur in sinking ETNP ODZ particles using sulfur K-edge X-ray absorption spectroscopy (XAS). During incubations, sinking aggregates were macroscopic ( $>1 \mathrm{~mm}$ ), composed of dark particles bound in a fluffy near-transparent matrix (fig. S2). This fluffy matrix dissolved during acid hydrolysis, leaving behind both discrete, $\sim 100-\mu \mathrm{m}$-long particles as well as more diffuse solids (Fig. 2). Sulfur in the hydrolysable matrix is relatively oxidized, in the form of sulfate esters and some sulfonates (Fig. 3). This material is consistent with the presence of sulfated polysaccharides, which are abundant constituents of exocellular polymers exuded by diatoms and other algae (27) and have been implicated in marine snow formation $(28,29)$. Polysaccharide exopolymers are likely sinks for sulfide in sinking particles, as sulfide can convert them to more hydrolysis-resistant forms (30).

The speciation of sulfur in the discrete, hydrolysis-resistant particles contrasts the largely oxidized organic sulfur in the hydrolysable matrix. Hydrolysis-resistant $S$ is present primarily as organic sulfides, with smaller amounts of aromatics, disulfides, and more oxidized forms (table S2). We found no evidence of elemental S, pyrite, or a sulfate background within the filters, which demonstrates that the radiolabeled $\mathrm{S}$ product from shipboard incubations is predominantly organic sulfur. Discrete particles in Regions 0 and 2 consist mostly of alkyl sulfides $(75.4 \pm 5.9 \%$, mean $\pm 1 \sigma$ for 'type 1', see table S2) with only a few percent each of sulfonates, esters and disulfides. In contrast, diffuse materials in Region 1 and a spot within the large particle from Region 2 
('type 2') are more enriched in sulfonates, sulfate esters and disulfides, with only $40.4( \pm 2.7 \%)$ sulfides.

Spatial differences in the speciation of organic sulfur likely reflect heterogeneities in the sources and types of organic matter that combine to form large marine particles. Sources of organic sulfides include both S-bearing amino acids in proteins that survived strong acid hydrolysis, as well as OM sulfurization reactions (31). Similarly, sulfonates and esters can represent primary biogenic sulfur from organisms in the surface ocean $(32,33)$, like the hydrolyzable exopolymers, or they can also be produced during OM sulfurization reactions alongside organic sulfides, disulfides, and aromatics (34). XAS results integrate organic $\mathrm{S}$ formed both before and during field incubations, so any combination of these organic $S$ forms could be the products of de novo sulfurization during shipboard incubations. Still, it is clear that that hydrolysisresistant OM can be a significant sink for the sulfide produced during particle-hosted MSR.

The organic S production we observe in sinking particles is sufficient to drive a significant change in the properties of the OM sinking to, and potentially preserved in, underlying marine sediments. Sulfurization involves cross-linking and rearrangement of organic molecules, which is thought to enhance the preservation potential of OM by reducing its compatibility with exoenzymes $(35,36)$. The extent of sulfurization is reflected in the molar $\mathrm{S}: \mathrm{C}$ ratio of $\mathrm{OM}$, which ranges from typically $\leq 1 \%$ for fresh algal biomass to $3-5 \%$ in many black shales $(13,37,38)$. If we assume that roughly $80 \%$ of the original $5 \mathrm{mg}(20 \mathrm{mg}) \mathrm{C}$ in each bottle from the $143-\mathrm{m}$ high-flux trap $(n=4)$ dissolved during hydrolysis (32), then an average of $0.83 \mu \mathrm{mol}$ organic $\mathrm{S}$ accumulated in a pool of $\sim 80-340 \mu \mathrm{mol}$ C over the course of the 24-hours incubation. By this calculation, the molar S:C ratio of non-hydrolyzable organic matter increased by roughly $0.3-1.1 \%$ per day, which is the right order of magnitude to generate "strongly sulfurized" OM (S:C $\geq 3 \mathrm{~mol} \%$ ) within a few days of sinking through the water column. Particles therefore appear to be a feasible source of sulfurized OM to marine sediments, at least under sufficiently reducing and high-particle-flux conditions. The majority of hydrolysable, unsulfurized biomass is then remineralized by microbial processes before deeper burial (39), leaving behind the sulfurized component. Particlehosted sulfurization could thus provide an explanation for observations of high OM burial in sediments underlying ODZs that do not intersect the sediment-water interface (40).

The organic S speciation in modern ODZ particles is also very similar to that reported from ancient kerogens in black shales from Ocean Anoxic Event 2 (13) (Fig. 3), which have sequestered vast amounts of OM for the last 94 million years (41). During this event, much of the southern proto-North Atlantic was sulfidic and preserved particularly S-rich OM, which could be the result of rapid sulfurization in sinking particles (13). The hydrolysis-resistant organic $\mathrm{S}$ in these shales, like that in ODZ particles, consists mostly of organic sulfides, with $\sim 10 \%$ contributions each from disulfides, aromatics, and sulfonates. The intriguing resemblance between actively sulfurizing particulate $\mathrm{OM}$ and ancient $\mathrm{OM}$ in shales allows for the interpretation that the same reactions that sulfurize OM in modern ODZ particles also facilitated elevated $\mathrm{OM}$ burial during periods of much more intense $\mathrm{O}_{2}$ depletion in Earth history. Particle-hosted OM sulfurization is thus a potentially powerful mechanism to enhance OM preservation in sediments under anoxic conditions.

In modern ODZs, rates of particle-hosted MSR and OM sulfurization appear to be highly variable in both time and space, making any attempt to estimate the global scale of their effects on organic carbon burial premature. Mechanistically, however, we might expect expanding ODZs to likewise expand the scale of marine particle-hosted OM sulfurization in the ocean. This would represent a negative feedback with climate and atmospheric $\mathrm{CO}_{2}$ : elevated $\mathrm{CO}_{2}$ leads to $\mathrm{ODZ}$ expansion that then drives enhanced $\mathrm{CO}_{2}$ sequestration in the form of sedimentary OM. Future research using this sampling approach will allow us to quantify the significance and environmental sensitivities of particle-hosted MSR and OM sulfurization on a global scale.

\section{REFERENCES AND NOTES}

1. J. Karstensen, L. Stramma, M. Visbeck, Oxygen minimum zones in the eastern tropical Atlantic and Pacific oceans. Prog. Oceanogr. 77, 331-350 (2008). doi:10.1016/j.pocean.2007.05.009

2. L. Stramma, E. D. Prince, S. Schmidtko, J. Luo, J. P. Hoolihan, M. Visbeck, D. W. R. Wallace, P. Brandt, A. Körtzinger, Expansion of oxygen minimum zones may reduce available habitat for tropical pelagic fishes. Nat. Clim. Chang. 2, 33-37 (2011). doi:10.1038/nclimate1304

3. S. Schmidtko, L. Stramma, M. Visbeck, Decline in global oceanic oxygen content during the past five decades. Nature 542, 335-339 (2017). doi:10.1038/nature21399 Medline

4. C. Deutsch, H. Brix, T. Ito, H. Frenzel, L. Thompson, Climate-forced variability of ocean hypoxia. Science 333, 336-339 (2011). doi:10.1126/science.1202422 Medline

5. Y. Takano, T. Ito, C. Deutsch, Projected Centennial Oxygen Trends and Their Attribution to Distinct Ocean Climate Forcings. Global Biogeochem. Cycles 32 , 1329-1349 (2018). doi:10.1029/2018GB005939

6. N. P. Revsbech, L. H. Larsen, J. Gundersen, T. Dalsgaard, O. Ulloa, B. Thamdrup, Determination of ultra-low oxygen concentrations in oxygen minimum zones by the STOX sensor. Limnol. Oceanogr. Methods 7, 371-381 (2009). doi:10.4319/lom.2009.7.371

7. P. N. Froelich, G. P. Klinkhammer, M. L. Bender, N. A. Luedtke, G. R. Heath, D. Cullen, P. Dauphin, D. Hammond, B. Hartman, V. Maynard, Early oxidation of organic matter in pelagic sediments of the eastern equatorial Atlantic: Suboxic diagenesis. Geochim. Cosmochim. Acta 43, 1075-1090 (1979). doi:10.1016/00167037(79)90095-4

8. M. T. Carolan, J. M. Smith, J. M. Beman, Transcriptomic evidence for microbial sulfur cycling in the eastern tropical North Pacific oxygen minimum zone. Front. Microbiol. 6, 334 (2015). doi:10.3389/fmicb.2015.00334 Medline

9. D. E. Canfield, F. J. Stewart, B. Thamdrup, L. De Brabandere, T. Dalsgaard, E. F. Delong, N. P. Revsbech, O. Ulloa, A cryptic sulfur cycle in oxygen-minimum-zone waters off the Chilean coast. Science 330, 1375-1378 (2010). doj:10.1126/science.1196889 Medline

10. T. M. Conway, S. G. John, The cycling of iron, zinc and cadmium in the North East 
Pacific Ocean - Insights from stable isotopes. Geochim. Cosmochim. Acta 164 , 262-283 (2015). doi:10.1016/igca.2015.05.023

11. M. R. Raven, A. L. Sessions, J. F. Adkins, R. C. Thunell, Rapid organic matter sulfurization in sinking particles from the Cariaco Basin water column. Geochim. Cosmochim. Acta 190, 175-190 (2016). doi:10.1016/i.gca.2016.06.030

12. J. D. Owens, C. T. Reinhard, M. Rohrssen, G. D. Love, T. W. Lyons, Empirical links between trace metal cycling and marine microbial ecology during a large perturbation to Earth's carbon cycle. Earth Planet. Sci. Lett. 449, 407-417 (2016). doi:10.1016/j.epsl.2016.05.046

13. M. R. Raven, D. A. Fike, A. S. Bradley, M. L. Gomes, J. D. Owens, S. A. Webb, Paired organic matter and pyrite $\delta^{34} \mathrm{~S}$ records reveal mechanisms of carbon, sulfur, and iron cycle disruption during Ocean Anoxic Event 2. Earth Planet. Sci. Lett. 512, $27-$ 38 (2019). doi:10.1016/i.epsl.2019.01.048

14. O. Ulloa, D. E. Canfield, E. F. DeLong, R. M. Letelier, F. J. Stewart, Microbial oceanography of anoxic oxygen minimum zones. Proc. Natl. Acad. Sci. U.S.A. 109, 15996-16003 (2012). doi:10.1073/pnas.1205009109 Medline

15. M. W. Smith, L. Zeigler Allen, A. E. Allen, L. Herfort, H. M. Simon, Contrasting genomic properties of free-living and particle-attached microbial assemblages within a coastal ecosystem. Front. Microbiol. 4, 120 (2013). doi:10.3389/fmicb.2013.00120 Medline

16. B. M. Fuchs, D. Woebken, M. V. Zubkov, P. Burkill, R. Amann, Molecular identification of picoplankton populations in contrasting waters of the Arabian Sea. Aquat. Microb. Ecol. 39, 145-157 (2005). doi:10.3354/ame039145

17. D. J. Janssen, T. M. Conway, S. G. John, J. R. Christian, D. I. Kramer, T. F. Pedersen, J. T. Cullen, Undocumented water column sink for cadmium in open ocean oxygen-deficient zones. Proc. Natl. Acad. Sci. U.S.A. 111, 6888-6893 (2014). doi:10.1073/pnas.1402388111 Medline

18. A. L. Shanks, M. L. Reeder, Reducing microzones and sulfide production in marine snow. Mar. Ecol. Prog. Ser. 96, 43-47 (1993). doi:10.3354/meps096043

19. D. Bianchi, T. S. Weber, R. Kiko, C. Deutsch, Global niche of marine anaerobic metabolisms expanded by particle microenvironments. Nat. Geosci. 11, 263-268 (2018). doi:10.1038/s41561-018-0081-0

20. Details are provided in the materials and methods section of the supplementary materials available online.

21. B. A. S. Van Mooy, R. G. Keil, Aquatic sample analysis system, U.S. Patent 9,188,512 (2015).

22. H. Ploug, Small-scale oxygen fluxes and remineralization in sinking aggregates. Limnol. Oceanogr. 46, 1624-1631 (2001). doi:10.4319/lo.2001.46.7.1624

23. A. L. Alldredge, Y. Cohen, Can microscale chemical patches persist in the sea? Microelectrode study of marine snow, fecal pellets. Science 235, 689-691(1987). doi:10.1126/science.235.4789.689 Medline

24. B. B. Jørgensen, The Sulfur Cycle of a Coastal Marine Sediment (Limfjorden, Denmark). Limnol. Oceanogr. 22, 814-832 (1977). doi:10.4319/lo.1977.22.5.0814

25. E. L. Cavan, M. Trimmer, F. Shelley, R. Sanders, Remineralization of particulate organic carbon in an ocean oxygen minimum zone. Nat. Commun. 8, 14847 (2017). doi:10.1038/ncomms14847 Medline

26. M. H. Iversen, H. Ploug, Temperature effects on carbon-specific respiration rate and sinking velocity of diatom aggregates; potential implications for deep ocean export processes. Biogeosciences 10, 4073-4085 (2013). doi:10.5194/bg-104073-2013

27. E. L. McCandless, J. S. Craigie, Sulfated Polysaccharides in Red and Brown-Algae. Annu. Rev. Plant Physiol. 30, 41-53 (1979). doi:10.1146/annurev.pp.30.060179.000353

28. U. Passow, A. L. Alldredge, B. E. Logan, The role of particulate carbohydrate exudates in the flocculation of diatom blooms. Deep Sea Res. Part I Oceanogr. Res. Pap. 41, 335-357 (1994). doi:10.1016/0967-0637(94)90007-8

29. A. L. Alldredge, M. W. Silver, Characteristics, dynamics and significance of marine snow. Prog. Oceanogr. 20, 41-82 (1988). doi:10.1016/0079-6611(88)90053-5

30. M. D. Kok, S. Schouten, J. S. Sinninghe Damsté, Formation of insoluble, nonhydrolyzable, sulfur-rich macromolecules via incorporation of inorganic sulfur species into algal carbohydrates. Geochim. Cosmochim. Acta 64, 2689-2699 (2000). doi:10.1016/S0016-7037(00)00382-3

31. A. Amrani, Z. Aizenshtat, Mechanisms of sulfur introduction chemically controlled: $\delta^{34} \mathrm{~S}$ imprint. Organic Geochem. 35, 1319-1336 (2004). doi:10.1016/j.orggeochem.2004.06.019
32. A. Vairavamurthy, W. Zhou, T. Eglinton, B. Manowitz, Sulfonates: A novel class of organic sulfur compounds in marine sediments. Geochim. Cosmochim. Acta 58, 4681-4687 (1994). doi:10.1016/0016-7037(94)90200-3

33. M. R. Raven, D. A. Fike, M. L. Gomes, S. M. Webb, Chemical and Isotopic Evidence for Organic Matter Sulfurization in Redox Gradients Around Mangrove Roots. Front. Earth Sci. 7, 98 (2019). doi:10.3389/feart.2019.00098

34. A. M. Pohlabeln, G. V. Gomez-Saez, B. E. Noriega-Ortega, T. Dittmar, Experimental Evidence for Abiotic Sulfurization of Marine Dissolved Organic Matter. Front. Mar. Sci. 4, 364 (2017). doi:10.3389/fmars.2017.00364

35. S. C. Brassell, C. A. Lewis, J. W. De Leeuw, F. de Lange, J. S. Damste, Isoprenoid thiophenes: Novel products of sediment diagenesis? Nature 320, 160-162 (1986). doi:10.1038/320160a0

36. M. Boussafir, F. Gelin, E. Lallier-Verges, S. Derenne, P. Bertrand, C. Largeau, Electron microscopy and pyrolysis of kerogens from the Kimmeridge Clay Formation, UK: Source organisms, preservation processes, and origin of microcycles. Geochim. Cosmochim. Acta 59, 3731-3747 (1995). doi:10.1016/0016-7037(95)00273-3

37. D. Dinur, B. Spiro, Z. Aizenshtat, The distribution and isotopic composition of sulfur in organic-rich sedimentary rocks. Chem. Geol. 31, 37-51 (1980). doi:10.1016/0009-2541(80)90066-2

38. D. A. Zaback, L. M. Pratt, Isotopic composition and speciation of sulfur in the Miocene Monterey Formation: Reevaluation of sulfur reactions during early diagenesis in marine environments. Geochim. Cosmochim. Acta 56, 763-774 (1992). doi:10.1016/0016-7037(92)90096-2

39. H. E. Hartnett, R. G. Keil, J. I. Hedges, A. H. Devol, Influence of oxygen exposure time on organic carbon preservation in continental margin sediments. Nature 391, 572-575 (1998). doi:10.1038/35351

40. T. F. Pedersen, G. B. Shimmield, N. B. Price, Lack of enhanced preservation of organic matter in sediments under the oxygen minimum on the Oman Margin. Geochim. Cosmochim. Acta 56, 545-551 (1992). doi:10.1016/00167037(92) $90152-9$

41. J. D. Owens, T. W. Lyons, C. M. Lowery, Quantifying the missing sink for global organic carbon burial during a Cretaceous oceanic anoxic event. Earth Planet. Sci. Lett. 499, 83-94 (2018). doi:10.1016/i.epsl.2018.07.021

42. S. M. Webb, The MicroAnalysis Toolkit: X-ray Fluorescence Image Processing Software. AIP Conf. Proc. 1365, 196-199 (2011). doi:10.1063/1.3625338

43. S. M. Webb, SIXpack: A graphical user interface for XAS analysis using IFEFFIT. Phys. Scr. 2005, 1011 (2005). doi:10.1238/Physica. Topical.115a01011

44. A. H. Devol, R. Keil, G. Rocap, C. Haskins, "CTD bottle data for all CTD casts during R/V Roger Revelle RR1804, RR1805 cruises in the Eastern Tropical North Pacific Ocean, from March to April 2018" (2019); www.bcodmo.org/dataset/779185/data.

\section{ACKNOWLEDGMENTS}

This work was made possible through the support and generosity of Alan Devol, Gabrielle Rocap, Jaqui Neibauer, and Megan Duffy at the U. of Washington, David Fike at Washington U. in St. Louis, and Victoria Orphan and Stephannie Connon at Caltech. Special thanks are also due to Molly O'Beirne (U. Pittsburgh) and the full science party and crew of the R/V Roger Revelle (RR1805). Funding: Financial support was provided under NSF Dimensions of Biodiversity award \#1542240 (to G. Rocap, R. Keil et al.) and the Agouron Institute Geobiology Postdoctoral Fellowship (to M.R.R.). Use of the Stanford Synchrotron Radiation Lightsource, SLAC National Accelerator Laboratory (proposal 5359) is supported by the U.S. Department of Energy, Office of Science, Office of Basic Energy Sciences under Contract No. DE-AC02-76SF00515. Author contributions: M.R.R. designed the study, conducted experiments, analyzed results, and wrote the text; R.G.K. designed the field expedition and collected particle material; S.M.W. helped collect and interpret X-ray absorption spectrometric data; and all authors contributed to the final manuscript. Competing interests: The authors declare no competing interests. Data and materials availability: All of the processed data analyzed in this study are included in this published article, its supplementary materials, and the referenced public database. Raw data files (XAS spectra and map files) are available from the corresponding author on request. 


\section{SUPPLEMENTARY MATERIALS}

science.sciencemag.org/cgi/content/full/science.abc6035/DC1

Materials and Methods

Figs. S1 to S3

Tables S1 and S2

References (42-44)

3 May 2020; accepted 3 December 2020

Published online 17 December 2020

10.1126/science.abc6035 


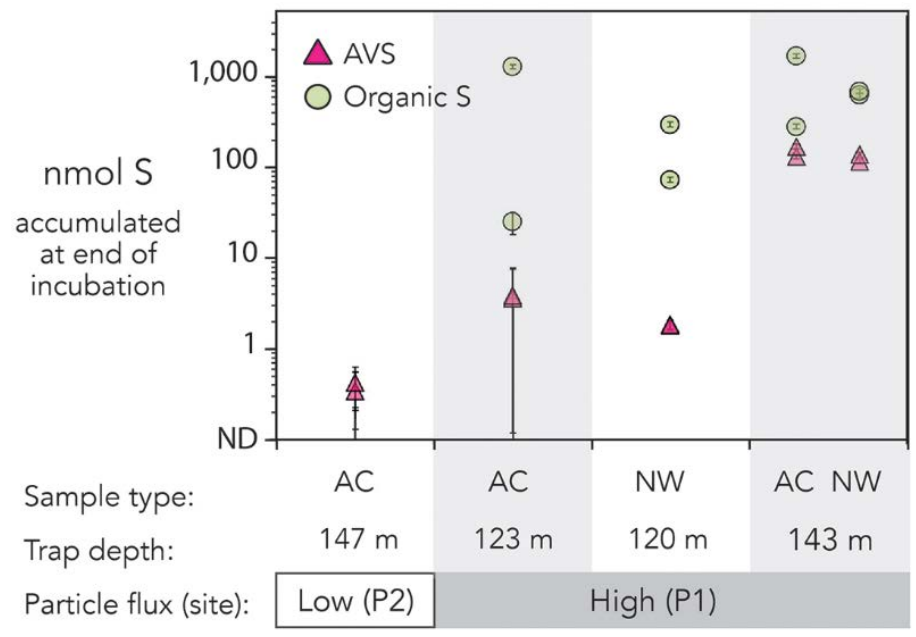

Fig. 1. Accumulation of radiolabeled $\mathrm{S}$ as acid-volatile and organic sulfur in particle incubations. Samples are arranged arbitrarily along the $x$-axis; note the $y$-axis is log scale. 'Sample type' describes whether particles were obtained from the strictly anoxic collector (AC) or recovered from the net wash (NW). Shading groups samples from individual deployments (table S1). Error bars that reach the $x$-axis indicate results that are not significantly different from zero. See fig. S1 for hydrographic context. 

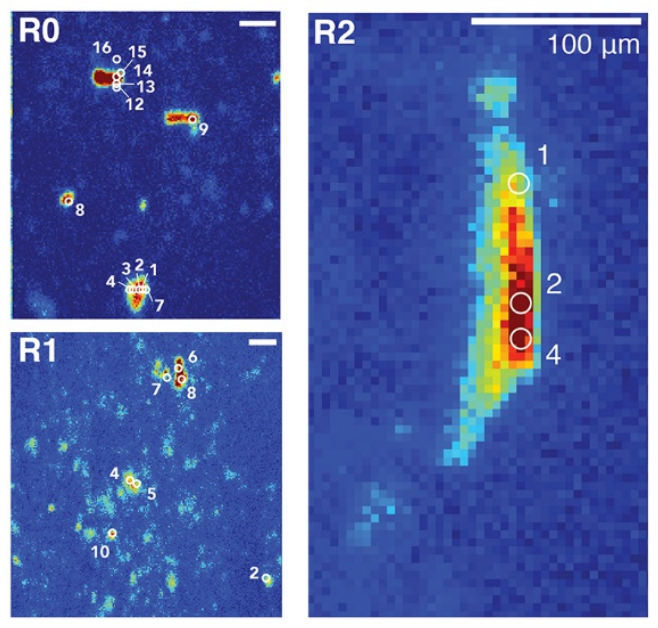

Fig. 2. Sinking particles on glass microfiber filters after hightemperature acid treatment. Selected map regions ( $R 0, R 1$, and $R 2$ ) show the spatial distribution of reduced S (2473.0 $\mathrm{eV}$ ) on filters, with color indicating relative absorbance from low (blue) to high (red). Numbered white circles show locations at which full spectra were collected; see fig. S3 and table S2 for full maps and data. All scale bars are $100 \mu \mathrm{m}$, and pixels represent $\sim 5 \mathrm{~m}^{2}$. 


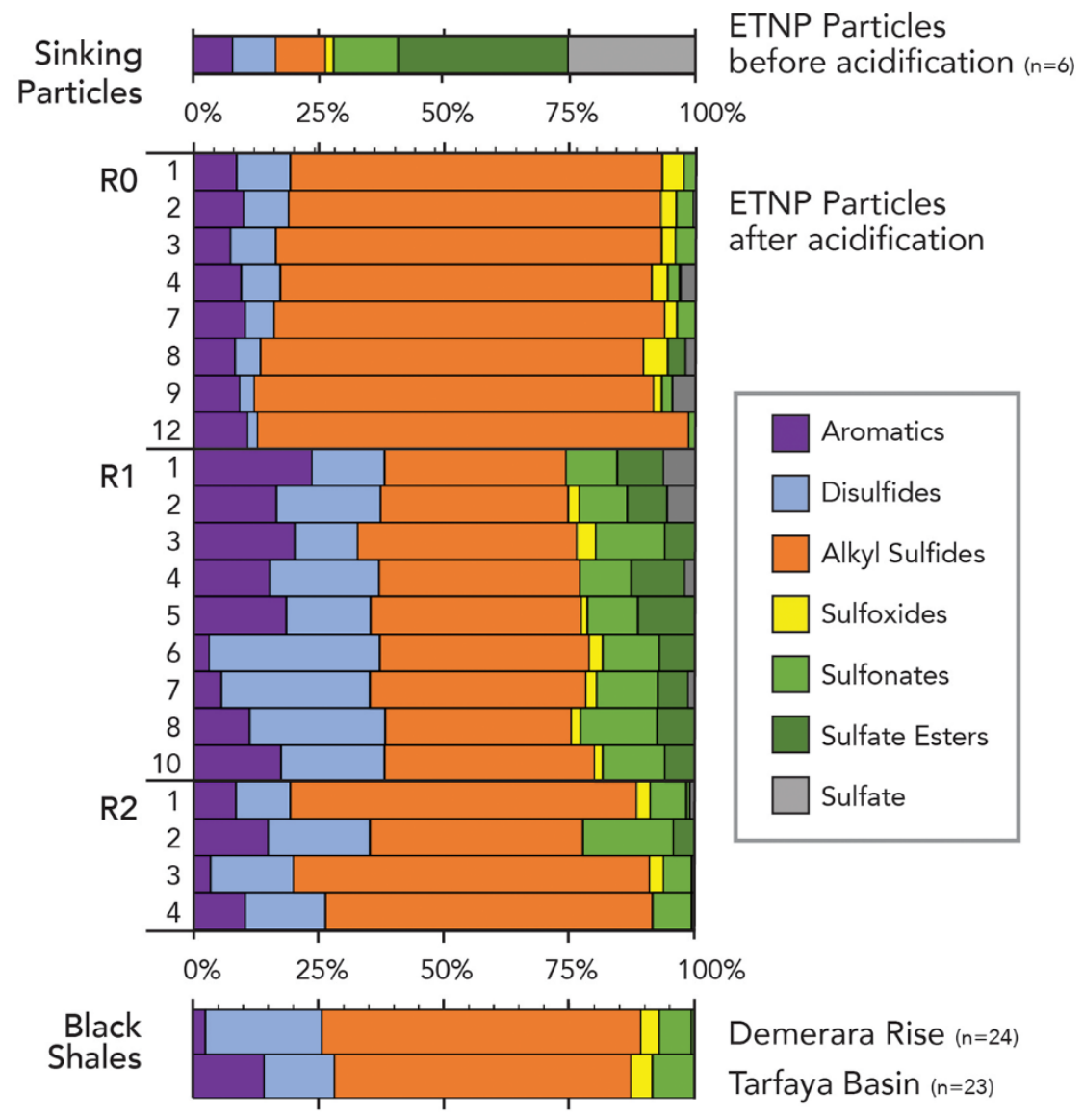

Fig. 3. Speciation of sulfur in ETNP particles and 94-million-yearold black shales. Bars represent the relative abundances of different sulfur moieties by linear deconvolution fitting in SIXPACK. Only high quality spot fits $\left(\mathrm{X}^{2}<2\right)$ are shown; see table $\mathrm{S} 2$ for uncertainties and fit parameters. Bars for black shales (13) and pre-acidification particles represent averages of all available data. Figure 2 includes a key to spot locations for acidified ETNP particles from regions RO, $\mathrm{R} 1$, and R2. 